\title{
Abundant expression of HMGB1 in human T-cell lymphotropic virus type I-infected T-cell lines and high plasma levels of HMGB1 in patients with adult T-cell leukemia
}

\author{
RYUICHIRO KIMURA ${ }^{1,2}$ and NAOKI MORI ${ }^{1}$ \\ ${ }^{1}$ Department of Microbiology and Oncology, Graduate School of Medicine, University of the Ryukyus, Nishihara, \\ Okinawa 903-0215; ${ }^{2}$ Transdisciplinary Research Organization for Subtropics and Island Studies, \\ University of the Ryukyus, Nishihara, Okinawa 903-0213, Japan
}

Received July 14, 2013; Accepted January 15, 2014

DOI: $10.3892 / \mathrm{ol} .2014 .1851$

\begin{abstract}
High mobility group box 1 (HMGB1) functions as a chromatin-associated nuclear protein and an extracellular signaling molecule. The concentration of HMGB1 protein and the expression of HMGB1 mRNA were analyzed by ELISA and polymerase chain reaction (PCR), respectively. The present study reports high plasma HMGB1 levels in patients with adult T-cell leukemia [ATL; which is caused by infection with human T-cell lymphotropic virus type I (HTLV-I)] compared with normal controls. In addition, HMGB1 was highly expressed in HTLV-I-infected T-cell lines compared with uninfected T-cell lines. The HTLV-I oncoprotein, Tax, induced extracellular release of HMGB1 in T cells. The results suggest that HMGB1 is a potential biomarker and a therapeutic target for ATL.
\end{abstract}

\section{Introduction}

Adult T-cell leukemia (ATL) is a highly aggressive malignant disease of $\mathrm{CD}^{+} \mathrm{T}$ cells, caused by human $\mathrm{T}$-cell lymphotropic virus type I (HTLV-I) (1). Infection with HTLV-1, the first oncogenic human retrovirus to be identified, also causes various chronic inflammatory disorders, including HTLV-I-associated myelopathy/tropical spastic paraparesis (2). The majority of infected individuals remain clinically asymptomatic, although $2-5 \%$ of HTLV-I-infected carriers develop ATL through genetic and epigenetic changes in the cell following a latent period of 40-60 years (3). Tax, the viral oncoprotein, plays a central role in tumorigenesis and contributes to the pathogenesis of ATL and inflammatory

Correspondence to: Dr Naoki Mori, Department of Microbiology and Oncology, Graduate School of Medicine, University of the Ryukyus, 207 Uehara, Nishihara, Okinawa 903-0215, Japan E-mail: naokimori50@gmail.com

Key words: HMGB1, adult T-cell leukemia, human T-cell lymphotropic virus type I, Tax diseases by inducing persistent activation of numerous cellular transcription factors, including nuclear factor- $\kappa \mathrm{B}$, cyclic adenosine 3',5'-monophosphate response element-binding protein and activator protein 1, leading to transactivation of cellular gene promoters (4). However, based on the absence of Tax protein expression in numerous late-stage ATL cells, this viral protein appears to be required only for the initiation of transformation $(3,4)$.

High mobility group box 1 (HMGB1) is an abundant and ubiquitous nuclear protein that binds to DNA and nucleosomes and induces structural changes in the chromatin fiber. It regulates numerous cellular activities, including transcription, replication and repair (5). In addition, HMGB1 is released from damaged, necrotic or activated immune cells and functions as an extracellular signaling molecule $(6,7)$. Thus, intranuclear and extranuclear HMGB1 are therapeutic targets for inflammation and infection (8). Previous studies have identified the roles of HMGB1 in cancer (9), with high protein expression in colon, breast, lung, prostate, cervical and gastric cancer, hepatocellular carcinoma and leukemia compared with normal tissues and healthy controls (10).

More recently, Zhang et al (11) have demonstrated that HMGB1 expression is upregulated by HTLV-I Tax in T cells. However, the expression levels of HMGB1 in HTLV-I-infected T-cell lines have not been determined. In the present study, the levels HMGB1 in several T-cell lines and in the plasma of patients with ATL were analyzed.

\section{Materials and methods}

Cell lines. The HTLV-I-infected T-cell lines, MT-2 (12), MT-4 (13), C5/MJ (14), SLB-1 (15), HuT-102 (16), MT-1 (17), TL-OmI (18) and ED-40515(-) (19), were cultured in RPMI-1640 medium supplemented with $10 \%$ heat-inactivated fetal bovine serum. MT-2, MT-4, C5/MJ and SLB-1 are HTLV-I-transformed T-cell lines established by an in vitro coculture protocol. MT-1, TL-OmI and ED-40515(-) are T-cell lines of leukemic cell origin established from patients with ATL. HuT-102 was also established from a patient with ATL and constitutively expresses viral genes, but its clonal origin is not clear. In JPX-9 cells, Tax is under the transcriptional control 
Table I. Primer sequences.

\begin{tabular}{lll}
\hline Gene name & \multicolumn{1}{c}{ Forward sequence } & \multicolumn{1}{c}{ Reverse sequence } \\
\hline HMGB1 & 5'-ATGGGCAAAGGAGATCCTAAGAA-3' & 5'-TTATTCATCATCATCATCTTCTT-3' \\
RAGE & 5'-ATGGAAACTGAACACAGGCC-3' & 5'-CACACATGTCCCCACCTTAT-3' \\
Tax & 5'-CCGGCGCTGCTCTCATCCCGGT-3' & 5'-GGCCGAACATAGTCCCCCAGAG-3' \\
GAPDH & 5'-GCCAAGGTCATCCATGACAACTTTGG-3' & 5'-GCCTGCTTCACCACCTTCTTGATGTC-3' \\
\hline
\end{tabular}

HMGB1, high mobility group box 1; RAGE, receptor for advanced glycation end products.

A

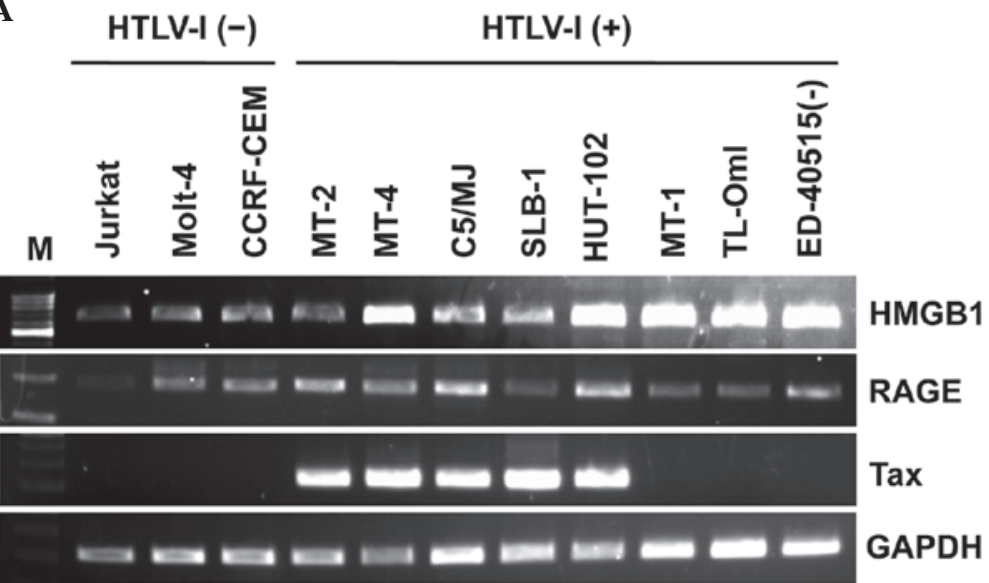

$\begin{array}{lllllllllllll}0.41 & 1.1 & 1.5 & 1.1 & 3.0 & 2.3 & 3.4 & 5.4 & 5.9 & 5.9 & 7.1 & \text { HMGB1/GAPDH }\end{array}$
B

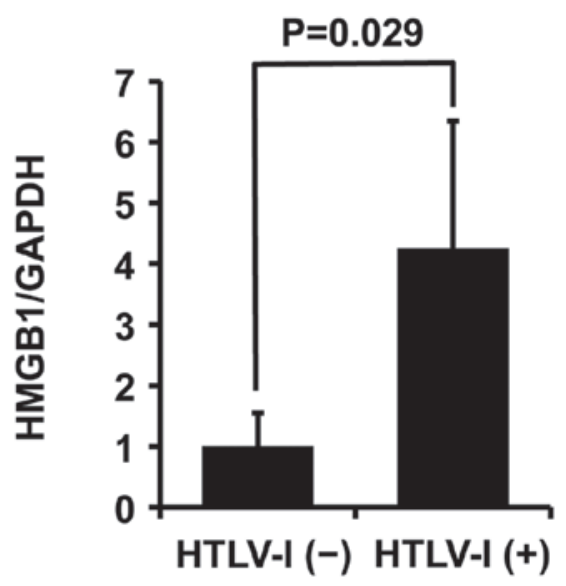

Figure 1. (A) Polymerase chain reaction analysis of HMGB1, RAGE, Tax and GAPDH mRNA expression in HTLV-I-infected T-cell lines. The HMGB1/GAPDH ratio was calculated by densitometric analysis of the bands. (B) Comparison of HMGB1 mRNA expression levels between HTLV-I-infected T-cell lines and uninfected T-cell lines. Data are presented as mean \pm standard deviation. HMGB1, high mobility group box 1; RAGE, receptor for advanced glycation end products; HTLV, human T-cell lymphotropic virus.

of the metallothionein gene promoter and can be induced by the addition of $\mathrm{CdCl}_{2}$ to the medium (20). Experiments using JPX-9 cells were carried out after a 24-h cultivation period in the absence and presence of $20 \mu \mathrm{M} \mathrm{CdCl}_{2}$.

Patients and plasma samples. The diagnosis of acute ATL was based on clinical features, hematological findings and the presence of anti-HTLV-I antibodies in the serum. Plasma samples were collected at the time of admission to the Naha City Hospital (Naha, Japan) prior to chemotherapy and stored at $-80^{\circ} \mathrm{C}$ until use. Informed consent was obtained from all blood donors.

Polymerase chain reaction (PCR). Total RNA was prepared from various cell cultures using TRIzol (Invitrogen Life Technologies, Carlsbad, CA, USA) according to the instructions provided by the manufacturer. First-strand cDNA was synthesized from $1 \mu \mathrm{g}$ total cellular RNA using a PrimeScript RT-PCR kit (Takara Bio Inc., Otsu, Japan) with random primers. The primer sequences for HMGB1, receptor for advanced glycation end products (RAGE), Tax and GAPDH are listed in Table I. PCR was halted during the exponential phase of DNA amplification and the reaction products were fractionated on $2 \%$ agarose gels and visualized by ethidium bromide staining. The obtained bands of amplified DNA were quantified using Image $\mathbf{J}$ (National Institutes of Health, Bethesda, MD, USA).

Assay for HMGB1. The concentrations of HMGB1 were measured in cultured supernatants from JPX-9 cells and plasma samples from patients and healthy donors using a commercially available ELISA kit II (Shino-Test Corporation, Tokyo, Japan) according to the manufacturer's instructions. The minimum detection level for HMGB1 was $1 \mathrm{ng} / \mathrm{ml}$.

Statistical analysis. Differences between groups were examined for statistical significance using the unpaired Student's t-test. $\mathrm{P}<0.05$ was considered to indicate a statistically significant difference.

\section{Results}

Expression of HMGB1 and RAGE mRNA in HTLV-I-infected T-cell lines. First, the expression levels of HMGB1, RAGE (HMGB1 receptor) and Tax were analyzed by PCR in eight HTLV-I-infected T-cell lines [MT-2, MT-4, C5/MJ, SLB-1, HuT-102, MT-1, TL-OmI and ED-40515(-)]. HTLV-I-transformed T-cell lines (MT-2, MT-4, C5/MJ and SLB-1) and HuT-102 constitutively expressed Tax mRNA, but ATL-derived T-cell lines [MT-1, TL-OmI and ED-40515(-)] 


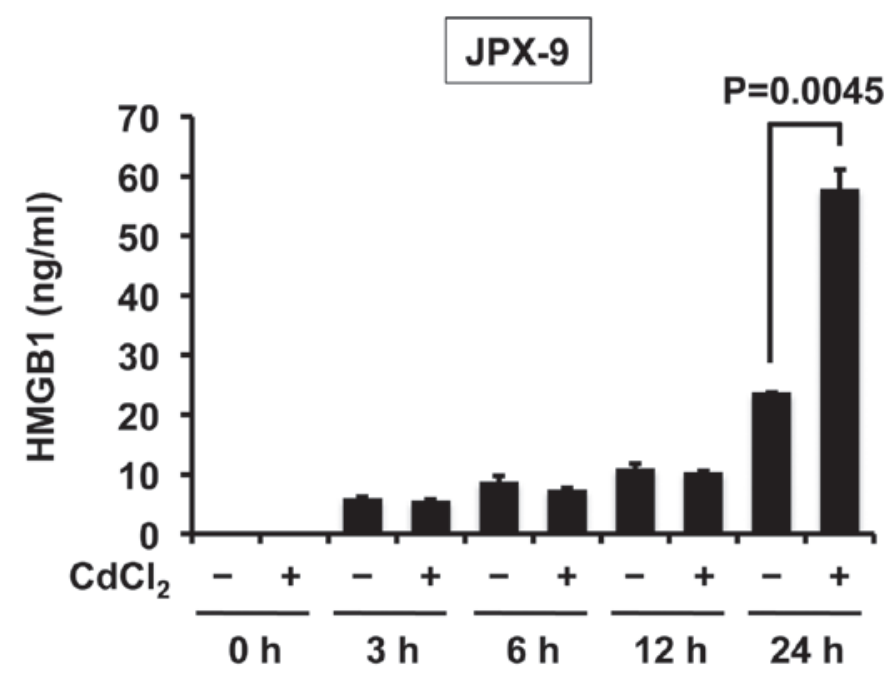

Figure 2. Tax enhances release of HMGB1 in T cells. JPX-9 cells were treated with or without $20 \mu \mathrm{M} \mathrm{CdCl}_{2}$ for the indicated time periods and the culture supernatants were harvested. HMGB1 protein concentrations in cultured supernatants from JPX-9 cells were measured by ELISA. Data are presented as mean \pm standard deviation. HMGB1, high mobility group box 1.

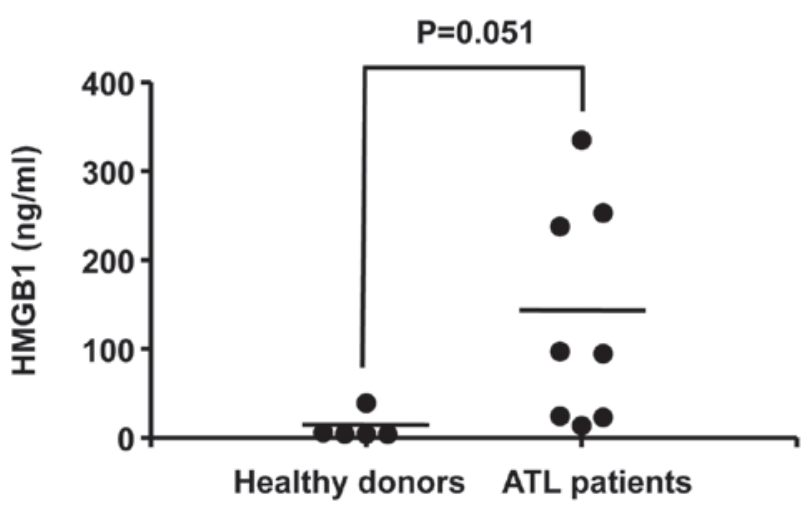

Figure 3. HMGB1 release is high in the plasma of ATL patients. Plasma HMGB1 levels in healthy donors $(n=5)$ and patients with acute ATL $(n=8)$. Horizontal lines represent mean values. HMGB1 protein concentrations in plasma samples were measured using an ELISA. HMGB1, high mobility group box 1; ATL, adult T-cell leukemia.

did not (Fig. 1A). PCR also revealed high expression of HMGB1 mRNA in all HTLV-I-infected T-cell lines except MT-2 compared with uninfected T-cell lines (Jurkat, Molt-4 and CCRF-CEM), regardless of Tax expression (Fig. 1A). The relative expression of HMGB1 in HTLV-I-infected T-cell lines was four-fold higher than in uninfected T-cell lines (Fig. 1B). By contrast, RAGE was expressed in all T-cell lines except Jurkat, regardless of HTLV-I infection, although its expression levels varied widely (Fig. 1A).

Tax protein enhances HMGB1 release in T cells. Next, the study sought to discern whether Tax induces the release of HMGB1 in T cells. Treatment of JPX-9 cells (a Jurkat subline that carries the Tax gene under the control of the metallothionein gene promoter) with $\mathrm{CdCl}_{2}$ rapidly induced Tax expression (20). ELISA revealed that Tax enhanced the release of HMGB1 in $\mathrm{T}$ cells in the $24 \mathrm{~h}$ after treatment with $\mathrm{CdCl}_{2}$ (Fig. 2).

Plasma levels of HMGB1 in patients with ATL. Finally, HMGB1 levels in the plasma of ATL patients were investigated.
The plasma levels of HMGB1 in patients with acute ATL $(n=8)$ tended to be higher than those in healthy donors $(n=5)$, albeit without statistical significance $(\mathrm{P}=0.051)$ (Fig. 3). The mean plasma HMGB1 levels in ATL patients (134 ng/ml) were ten-fold higher than those of healthy donors $(11 \mathrm{ng} / \mathrm{ml})$. These data demonstrate that HMGB1 is markedly released in the plasma of ATL patients.

\section{Discussion}

The HTLV-I transactivator protein, Tax, is a protein of significant interest in HTLV-I pathogenesis, as it is a potent activator of a variety of transcription pathways and is in itself sufficient to immortalize $\mathrm{T}$ cells in vitro. Thus, it plays an important role in cellular transformation $(3,4)$. Recently, it has been reported that Tax is involved in upregulation of HMGB1 expression by interaction with CCAAT/enhancer binding protein (11). The present study found that HMGB1 mRNA was abundantly expressed in HTLV-I-infected T-cell lines. In addition, Tax increased HMGB1 secretion in $\mathrm{T}$ cells. These results are consistent with those reported previously (11). Tax expression did not correlate with the upregulation of HMGB1 mRNA in HTLV-I-infected T-cell lines. However, significantly higher plasma levels of HMGB1 were noted in ATL patients with peripheral leukemic cells negative for Tax protein than in healthy donors. Thus, it may be that another factor is essential for the induction of HMGB1 expression and secretion in ATL.

While the exact function of HMGB1 protein is not clear at present, it is reported to play important roles in sustained angiogenesis, evasion of apoptosis, growth signal self-sufficiency, insensitivity to antigrowth signals, the inflammatory microenvironment, immortalization, tissue invasion and metastasis in cancer cells (10). In addition, HMGB1 is reported to promote drug resistance in osteosarcoma (21). Previous studies have also shown that endogenous HMGB1 regulates autophagy (22) and that HMGB1-induced autophagy promotes resistance to chemotherapy in leukemia cells (23). 
Therefore, HMGB1 appears to play important roles in malignant progression, inflammation, organ infiltration and drug resistance in HTLV-I-associated diseases, including ATL. These findings suggest that HMGB1 is a potential biomarker and therapeutic target for ATL.

In conclusion, the present study demonstrated that there are elevated plasma HMGB1 levels in patients with ATL and an abundant HMGB1 expression in HTLV-I-infected T-cell lines.

\section{Acknowledgements}

The authors thank Dr Masataka Nakamura for providing JPX-9 cells, Dr Michiyuki Maeda for providing ED-40515(-) cells and the Fujisaki Cell Center, Hayashibara Biomedical Laboratories (Okayama, Japan) for providing HuT-102, C5/MJ and MT-1 cells. The authors would also like to thank Naha City Hospital (Naha, Japan) for providing plasma samples from patients.

\section{References}

1. Yoshida M, Miyoshi I and Hinuma Y: Isolation and characterization of retrovirus from cell lines of human adult T-cell leukemia and its implication in the disease. Proc Natl Acad Sci USA 79: 2031-2035, 1982.

2. Watanabe T: HTLV-1-associated diseases. Int J Hematol 66: 257-278, 1997.

3. Matsuoka M and Jeang KT: Human T-cell leukaemia virus type $1($ HTLV-1) infectivity and cellular transformation. Nat Rev Cancer 7: 270-280, 2007.

4. Grassmann R, Aboud M and Jeang KT: Molecular mechanisms of cellular transformation by HTLV-1 Tax. Oncogene 24: 5976-5985, 2005.

5. Hock R, Furusawa T, Ueda T and Bustin M: HMG chromosomal proteins in development and disease. Trends Cell Biol 17: 72-79, 2007.

6. Lotze MT and Tracey KJ: High-mobility group box 1 protein (HMGB1): nuclear weapon in the immune arsenal. Nat Rev Immunol 5: 331-342, 2005.

7. Dumitriu IE, Baruah P, Manfredi AA, Bianchi ME and Rovere-Querini P: HMGB1: guiding immunity from within. Trends Immunol 26: 381-387, 2005.

8. Andersson U and Tracey KJ: HMGB1 is a therapeutic target for sterile inflammation and infection. Annu Rev Immunol 29: 139-162, 2011.

9. Sims GP, Rowe DC, Rietdijk ST, Herbst R and Coyle AJ: HMGB1 and RAGE in inflammation and cancer. Annu Rev Immunol 28 367-388, 2010.
10. Tang D, Kang R, Zeh HJ III and Lotze MT: High-mobility group box 1 and cancer. Biochim Biophys Acta 1799: 131-140, 2010.

11. Zhang CG, Wang H, Niu ZG, Zhang JJ, Yin MM, Gao ZT and $\mathrm{Hu}$ LH: Tax is involved in up-regulation of HMGB1 expression levels by interaction with C/EBP. Asian Pac J Cancer Prev 14: 359-365, 2013

12. Miyoshi I, Kubonishi I, Yoshimoto S, Akagi T, Ohtsuki Y, Shiraishi Y, Nagata K and Hinuma Y: Type C virus particles in a cord T-cell line derived by co-cultivating normal human cord leukocytes and human leukaemic T cells. Nature 294: 770-771, 1981.

13. Yamamoto N, Okada M, Koyanagi Y, Kannagi M and Hinuma Y: Transformation of human leukocytes by cocultivation with an adult $\mathrm{T}$ cell leukemia virus producer cell line. Science 217: 737-739, 1982.

14. Popovic M, Sarin PS, Robert-Gurroff M, Kalyanaraman VS, Mann D, Minowada J and Gallo RC: Isolation and transmission of human retrovirus (human t-cell leukemia virus). Science 219: 856-859, 1983

15. Koeffler HP, Chen IS and Golde DW: Characterization of a novel HTLV-infected cell line. Blood 64: 482-490, 1984.

16. Poiesz BJ, Ruscetti FW, Gazdar AF, Bunn PA, Minna JD and Gallo RC: Detection and isolation of type $C$ retrovirus particles from fresh and cultured lymphocytes of a patient with cutaneous T-cell lymphoma. Proc Natl Acad Sci USA 77: 7415-7419, 1980

17. Miyoshi I, Kubonishi I, Sumida M, Hiraki S, Tsubota T, Kimura I, Miyamoto K and Sato J: A novel T-cell line derived from adult T-cell leukemia. Gann 71: 155-156, 1980.

18. Sugamura K, Fujii M, Kannagi M, Sakitani M, Takeuchi M and Hinuma Y: Cell surface phenotypes and expression of viral antigens of various human cell lines carrying human T-cell leukemia virus. Int J Cancer 34: 221-228, 1984.

19. Maeda M, Shimizu A, Ikuta K, Okamoto H, Kashihara M, Uchiyama T, Honjo $\mathrm{T}$ and Yodoi J: Origin of human T-lymphotrophic virus I-positive $\mathrm{T}$ cell lines in adult $\mathrm{T}$ cell leukemia. Analysis of T cell receptor gene rearrangement. J Exp Med 162: 2169-2174, 1985.

20. Ohtani K, Nakamura M, Saito S, Nagata K, Sugamura K and Hinuma Y: Electroporation: application to human lymphoid cell lines for stable introduction of a transactivator gene of human T-cell leukemia virus type I. Nucleic Acids Res 17: 1589-1604, 1989.

21. Huang J, Ni J, Liu K, Yu Y, Xie M, Kang R, Vernon P, Cao L and Tang D: HMGB1 promotes drug resistance in osteosarcoma. Cancer Res 72: 230-238, 2012.

22. Tang D, Kang R, Livesey KM, Cheh CW, Farkas A, Loughran P, Hoppe G, Bianchi ME, Tracey KJ, Zeh HJ III and Lotze MT: Endogenous HMGB1 regulates autophagy. J Cell Biol 190: 881-892, 2010.

23. Liu L, Yang M, Kang R, Wang Z, Zhao Y, Yu Y, Xie M, Yin X, Livesey KM, Lotze MT, Tang D and Cao L: HMGB1-induced autophagy promotes chemotherapy resistance in leukemia cells. Leukemia 25: 23-31, 2011. 